\title{
Investigation into the Changes in Bending Stiffness of a Textile Reinforced Composite due to In-Plane Fabric Shear: Part 1 - Experiment
}

\author{
Cynthia Mitchell, Lisa Dangora, Christie Bielmeier, James Sherwood* \\ Department of Mechanical Engineering, University of Massachusetts Lowell \\ One University Ave., Lowell, MA 01854, USA
}

*Corresponding Author james_sherwood@uml.edu

\begin{abstract}
A study to investigate the factors that contribute to the variation among the stiffnesses of consolidated composite plates reinforced by plain-weave fabrics with various degrees of in-plane shear is presented. The first part of the two-part study focuses on the experiments performed. Threepoint bend tests were used to measure the effective stiffness of the composite plates along the global $\mathrm{X}$ and $\mathrm{Y}$ axes, which were aligned with the weft and warp orientations, respectively, in the undeformed configuration at $0^{\circ}$ of shear. The warp yarns were sheared $0^{\circ}, 10^{\circ}, 20^{\circ}, 25^{\circ}$ and $30^{\circ}$ toward the weft yarns. It was observed that as the shear angle in the plates increased, the thickness of the plates also increased. An increase in stiffness for bending in X-direction with increasing shear angle was observed as was expected, but the change in stiffness for bending in Y-direction was observed to be inconsistent with the expected decrease with increasing degree of shear.
\end{abstract}

\section{Keywords}

A. Fabrics/textiles; B. Mechanical Properties; C. Laminate Mechanics; D. Shear Deformation 


\section{INTRODUCTION}

Many industries are continuing to expand their applications for fiber-reinforced composites [1-4]. Textile reinforcements are particularly attractive because they can be relatively inexpensive and additionally save time in composite processing by allowing manufacturers to lay-up multiple plies and orientations in a single step [5-7]. As a result, many forming methods have been developed to use textiles for automated composite manufacturing processes (e.g., matched die forming, thermoforming, and hydroforming) that allow for relatively quick molding of two-dimensional sheets into three-dimensional parts [8].

As the fabric conforms to complex three-dimensional molds, there are three major modes of deformation occurring within the textile: the tows can stretch, the fabric can shear, and the tows can bend in-plane and out-of-plane. The primary mode of in-plane deformation is fabric shear, i.e. the tows rotate relative to one another within the plane of the fabric [9-16]. The current study solely focuses on shear deformation. An example of this shearing mechanism is shown Fig. 1, which depicts the deformation of a woven fabric resulting from the forming of a hemisphere. The tows that were originally mutually perpendicular rotate with respect to each other to conform to the compound curvature of the three-dimensional hemisphere. Because fiber-reinforced composites have directionally dependent material properties, it is important to track the evolution of the fiber reorientations and to understand how the local fabric alignments contribute to the overall effective stiffness of the composite part. Classical Laminate Theory (CLT) is the universally accepted solution for understanding the effects of the reorientations of unidirectional fibers on the mechanical properties of a composite material with a uniform volume fraction. Modifications to CLT are used to analyze the behavior of woven-fabric-reinforced composites; however these models assume the fibers are mutually perpendicular [17-19]. Nothing exists in the open literature to predict how the 
behavior of a woven-fabric-reinforced composite behaves when the fabric reinforcement within the composite has been sheared.

Due to this lack of understanding, composite structures are often designed using a designbuild-test methodology. This approach relies heavily on experimental processes to determine the deformation of the fabric during the manufacturing process and the resulting structural behavior of the final composite part. The design-build-test methodology is very time consuming and expensive, so models are often used as a complementary virtual design tool to aid in predicting the final orientations of the fiber tows within a part as a result of manufacturing [20-34]. A recent investigation by Mitchell et al. [35] was performed to demonstrate how the output of such a simulation of the composite manufacturing process can facilitate a subsequent finite element model which would use the geometry of the deformed textile to predict the behavior of the final composite structure. A finite element model that can use the results of the manufacturing process to complete a structural analysis would be a very valuable virtual design tool. Linking the part stiffness back to the manufacturing steps would aid in the material selections and help determine the pre-manufacturing orientations of fabric reinforcements arranged in the charge.

To model the forming process, the mechanical behavior of the fabric must be characterized as input parameters for the finite element model of the manufacturing process. One popular method to measure the resistance of a fabric to in-plane shear is the picture-frame test (a.k.a. trellis-frame test, shear-frame test, rhombus test). The picture-frame test is performed by clamping a sample of fabric to a pin-jointed frame. A load is applied in the bias direction of the frame, which creates a state of pure shear in the fabric [9, 26-44]. An example of a picture-frame test is shown in Fig. 2(a). The test area is in the center of the fabric sample with the tows initially mutually perpendicular. The "arms" of the sample are clamped into the frame, and the cross-fibers in the arms are removed to 
ensure a state of pure shear in the test area $[9,39]$. The typical load vs. shear angle curve is shown in Fig. 2(b). When the fabric first begins to shear, the loads required to rotate the tows are relatively low. As the fabric continues to shear, it reaches a point where further rotation is hindered by the compaction of the tows against one another, thereby increasing the effective shear stiffness of the fabric. Once the tows can no longer compact, the fabric is said to have reached its "locking angle." At this point, the load required to further shear the fabric increases significantly, and the fabric tows begin to buckle out of the plane of the fabric [42]. Some researchers have observed large scatter in the resulting shear-stiffness curves from various normalized picture-frame tests [9]. This scatter has largely been attributed to misalignment of the sample within the frame. Misalignments between the fibers in the sample and the edges of the picture-frame will cause a mismatch in the shear angle calculated based on the frame displacement and the shear angle within the fabric sample [10-13]. Additionally, the level of tension present within the fiber tows has been demonstrated to influence the shear stiffness of a textile [14-16]. Thus, it is important to ensure proper fiber alignment and tow tension when installing the fabric in the picture frame device.

While extensive studies have been performed to investigate the shear deformation mechanics of fabrics during forming processes [9, 20-23, 34, 36-50], no previous studies examining how shearing of the fabric affects the composite structure were found in the open literature. A methodology to quantify the contribution of a sheared fabric ply to the effective stiffness is valuable to creating a finite element model that would be able to predict the behavior of composite materials with deformed reinforcements. The first step in developing such a methodology is to complete an experimental investigation to gain a quantitative understanding of the significance of fabric shear to the overall part stiffness. This paper presents an experimental program that was used to examine how in-plane shear within the fabric reinforcements affects the flexural behavior of a woven-glass 
polypropylene reinforced composite plate. The information gained from this study will be used to guide future research in incorporating the shear contribution into a modeling methodology.

\section{BACKGROUND}

Past studies have examined how the geometry of dry textile is affected by in-plane shear $[51,52]$. These studies include how the fiber tow width changes as the fabric experiences in-plane shear. Additionally, research has been performed exploring how the fabric thickness changes as a result of shear loading $[53,54]$. The current study investigates if and how the changes observed in the previous studies on dry fabrics will translate to changes in the textile reinforcement geometry after the fabric has been infused by a matrix. These changes have the potential to effect the fiber volume fraction, which directly effects the mechanical properties of the composite. To understand if the material properties of the consolidated textile-reinforced composites are affected by fabric shear, it is important to understand the textile's geometry within the composite. Sections 2.1 and 2.2 detail the previous studies on dry fabric. These studies will be used as a baseline for the current research on consolidated plates with sheared fabric reinforcements.

\subsection{Change in tow width due to in-plane shear}

Zhu et al. [52] performed extensive research into the deformation of a plain-weave fabric during the picture-frame test. Tow widths were measured and compared to the theoretical width of a yarn with a clamped-clamped boundary condition:

$$
w=w_{0} \cos \gamma
$$

where $w_{0}$ is the initial width of the yarn and $\gamma$ is the measured fabric shear angle. This equation assumes that the observed change in width is solely due to the shearing of the tow. Any possible lateral fiber compaction within the tow is neglected in this equation. Zhu et al. found that Eqn. 1 under-predicted the measured width for large shear angles and over-predicted the resulting tow 
widths for small shear angles. These discrepancies implied that the change in tow width was due to more than just the shearing of the tow and that compaction of the fibers within the fiber tows should be investigated.

McBride and Chen [51] performed bias-extension tests on various woven fabrics and employed the use of a stereomicroscope to observe how the fabric deformed in shear. The spacing of the crossover points was observed to remain constant with respect to the shear angle. However, the width of the tow was observed to decrease as the shear angle increased. This change was approximated by:

$$
t w(\theta)=w_{0}(\sin \theta)^{1-\left[\left(s_{0}-w_{0}\right) / \beta_{0}\right]}
$$

where $t w$ is the true width of the tow, $w_{0}$ is the width of the undeformed yarns, $s_{0}$ is the spacing between the crossover points in the undeformed fabric, $\beta_{0}$ is the half-period of the sinusoid describing the yarn crossover points calculated from the width and spacing of the tows, and $\theta$ is the angle between the warp and the weft tows. This equation generally overpredicted the compaction of the yarns as compared to experimental observations but generally was more accurate than ignoring the effect of lateral compaction of the yarns.

\subsection{Change in fabric-thickness due to in-plane shear}

Barburski et al. [53] investigated how pre-strain and shear affected the compressibility of knitted fabrics. The fabric was sheared or pre-strained a prescribed amount and clamped into a frame. The fabric was subsequently tested by applying a compressive load normal to the surface. The thickness of the fabric was reported at a pressure of $100 \mathrm{kPa}$ which is a load similar to what the fabric would see during a vacuum-assisted manufacturing process. It was observed that as the prestrain in the fabric was increased, the measured thickness of the fabric decreased. Conversely, as the shear angle of the fabric increased, the thickness of the fabric increased. 
A similar study was performed by Ivanov et al. [54] where they used laser scanning methods to investigate the change in thickness of several carbon fabrics. One method used lasers on each side of the fabric to track the thickness evolution of a single point. This method demonstrated that as the shear angle increased, the fabric thickness also increased. However, due to the topology of the fabric, these measurements were very noisy. Therefore, an additional method was developed by Ivanov et al. [54] in which the picture-frame test was stopped periodically and a scan of the fabric thickness over a prescribed line of the sample was performed. The trend for the evolution of the thickness was found to be different for various fabric architectures. For example, the twill-weave fabric displayed a quadratic increase in thickness with respect to the fabric shear angle, while the biaxial NCF exhibited more of a linear behavior with respect to the fabric shear angle. All samples showed a significant increase in sample thickness by $45^{\circ}$ of shear.

Each of these previous studies saw a change in thickness of the fabric as a function of fabric shear. Because the flexural stiffness of a plate is proportional to the cube of the thickness, it is critical to account for changes in thickness resulting from the forming process. This thickness increase will impact the effective stiffness of the final formed part and may lead to variations in thickness over the surface of a part due to differences in the degree of in-plane fabric shear from point to point.

\section{EXPERIMENTAL INVESTIGATIONS}

To investigate the effect of in-plane shear of the textile reinforcement on the resulting flexural properties of a flat fabric-reinforced composite plate, samples were fabricated with a prescribed uniform shear angle in the textile. This section describes the techniques used to make the samples as well as the tests performed to evaluate the bending stiffnesses of the composite plates. 


\subsection{Sample Fabrication}

Samples were manufactured using a plain-weave Fiber Glass Industries Twintex ${ }^{\circledR}$ fabric consisting of comingled fiberglass (reinforcement) and polypropylene (matrix) fibers. This material is attractive to the composites manufacturing industry because of the time benefits it offers to the manufacturing process as it avoids the need for a resin application step. Upon preheating the fabric in an oven, the polypropylene melts and automatically infuses the fibers with matrix material. Additionally, Twintex ${ }^{\circledR}$ was used in previous studies regarding the forming of fabric-reinforced composites $[9,28]$. The fabric architecture is depicted in Fig. 3, and the mechanical properties provided by the manufacturer [55] are given in Table 1 .

Three fabric samples were imaged using a Zeiss V20 Stereo Microscope. The width of the tows and the gaps between the tows were digitally measured at 10 locations within each sample. The measured dimensions are reported in Table 2. One example of such an image and measurements is shown in Fig. 4(a). To calculate the area of the fabric, five warp tows and five weft tows were carefully removed from the weave. The linear density of each tow, $\lambda_{\text {tow }}$, was determined by measuring the length and the mass of each specimen. The densities of polypropylene $\left(\rho_{p p}\right)$ and glass $\left(\rho_{\text {glass }}\right)$ are known values. The area of the tow was then calculated using:

$$
A_{\text {tow }}=\frac{\lambda_{\text {tow }}}{V F_{\text {glass }} \rho_{\text {glass }}+\left(1-V F_{\text {glass }}\right) \rho_{p p}}
$$

where the glass volume fraction, $V F_{\text {glass }}$, is $35 \%$ per the manufacturer's specifications [55].

The individual tows were imaged on the Zeiss V20 Stereo Microscope to measure the thickness of the tow and the overall thickness of the fabric. An example of these measurements for a weft tow is shown in Fig. 4(b). Measurements were made on no less than five samples for each dimension. The average dimensions are given in Table 2 . 
To ensure that each sample was uniformly sheared to the desired angle, the fabric was placed in a picture frame (Fig. 5(a)). The frame had an edge length of $254 \mathrm{~mm}$, and the edge of the test area had an edge length of $219 \mathrm{~mm}$. The cross tows were removed from the "arms" of the sample to develop a uniform state of shear in the central region. The frame was displaced until the fabric reached the desired shear angle. Note that the shear angle of the fabric was measured independently of the shear angle of the picture frame. The bolts on the frame were then tightened such that the fabric would not relax (Fig. 5(b)). The fabric was subsequently lined with nonporous teflon paper and rubber to reduce bleed-out of the matrix material and to create a smooth plate surface (Fig. 5(c)). To ensure that the fabric would remain flat inside the vacuum bag, an aluminum plate was custom made to the diamond-shaped dimensions of the sheared test area (Fig. 5(d)). Once the layup was completed, the entire setup was vacuum bagged and placed in the oven (Fig. 5(e)).

The temperature of the sample was monitored until it reached the melting temperature of the polypropylene $\left(180^{\circ} \mathrm{C}[55]\right)$. At this point, the temperature was held constant as the polypropylene fibers melted and formed the polypropylene matrix under the vacuum condition. When the temperature of the sample reached $180^{\circ} \mathrm{C}$, the oven was turned off, and the vacuum was maintained while the sample cooled to room temperature during the consolidation of the polypropylene. After the matrix was completely consolidated, the sample was removed from the vacuum bag.

The consolidated samples were cut into $127-\mathrm{mm} \times 127-\mathrm{mm}$ square plates as shown in Fig. 6(a). The plates were cut such that the weft tows were parallel to one edge of the plate which will be referred to as the global X-axis. The warp tows were rotated from the other edge, referred to as the global Y-axis of the plate by the shear angle $(\gamma)$. This relationship between the shear angle and the warp and weft tows, as well as the relative orientation of the fabric within the global X-Y system are presented in Fig. 6(b). 
Plates were manufactured for shear angles between $0^{\circ}$ and $30^{\circ}$ in $10^{\circ}$ increments. The upper limit of $30^{\circ}$ was chosen due to the geometric limitation of the shear frame. After the initial testing had been performed on these plates, it was concluded that more data were needed to understand the behavior of the plates with shear angles between $20^{\circ}$ and $30^{\circ}$, so plates with a $25^{\circ}$ shear angle were added to in the study. For each angle, three samples were manufactured to explore repeatability.

\subsection{Measured Change in Tow Width as a Function of In-Plane Shear}

The widths of the weft tows were measured at 10 locations on each plate. Each measurement was taken at various positions along the $\mathrm{X}$-axis. However, no pattern was observed as the tow's width remained relatively unchanged along its longitudinal axis. The average tow width as a function of the shear angle in the fabric reinforcement can be seen in Fig. 7. The error bars denote one standard deviation. The measurement data indicate that the tow width decreased as the shear angle within the reinforcement increased, similar to the results from the literature for dry fabric [53, 54]. The data were also compared to the calculated tow width based on a pure geometric deformation without compaction as suggested by Zhu et al. (Eqn. 1) and deformation considering tow compaction as modeled by McBride and Chen (Eqn. 2). In the consolidated state, the width of the tow as a function of shear angle follows the trends predicted by Zhu et al. as a geometric deformation. This behavior contradicts the previous results seen in the literature which indicated that the tow width was narrower than the width calculated for a pure geometric deformation [51, $52]$.

The difference can be attributed to the state of the fabric during the tow measurements. In this study, the width of the tow was measured after the Twintex® had been consolidated in the vacuum-bag process. The width of the weft tows in the dry, undeformed fabric is narrower than the width of the weft tows measured for any of the plates. While the tows may be experiencing lateral 
compaction in the shear frame prior to consolidation, the pressure applied by the vacuum bag when forming the plates counteracts any possible lateral compaction. It is important to note that the gap between the weft tows in this fabric is significant, allowing the fibers to spread during consolidation. A similar phenomenon may not be observed with a tighter weave. Future research on a range of weaves (from loose to tight) could be completed to characterize the behavior of the tows for a range of fabric geometries during shearing and the subsequent consolidation processing steps.

\subsection{Measured Change in Thickness as a Function of In-Plane Shear}

The thickness of each plate was measured at 16 discrete locations on the plate. The measurements were averaged, and the relationship between degree of shear and plate thickness is shown in Fig. 7Error! Reference source not found.. The error bars in the plot denote one standard deviation. The large scatter in the data is due to thickness variations resulting from the use of a flexible mold in the vacuum-bagging process. For the data presented in the current study, the scatter appears large because the samples were constructed from a single ply of fabric, resulting in relatively thin plates. However, the scatter remains consistent with the average trends seen in the data. Similar to previous findings for dry fabrics [53, 54], the thickness of the composite plate increased with increasing shear angle. The observed change in thickness is an important aspect of the forming process that must be included in an analysis when predicting the deformation of textiles during the forming process. Two mathematical equations were fit to the data: a trigonometric function and a cubic polynomial. Both fits were compared to the experimental data in Fig. 8 . The trigonometric function was based on a conservation of volume argument. The equation predicts the thickness of the plates using:

$$
t(\gamma)=\frac{t_{0}}{\cos (\gamma)}
$$


The conservation of volume argument assumes the increase in thickness is a direct result of the decrease in the test area during the progression of the picture-frame test. While it serves as a reasonable approximation for the change in thickness, it generally over-predicts the measured thickness. This mismatch is due to the nature of the fibrous material. While the test area is decreasing during the picture frame test, the volume is conserved by not only a change in thickness, but also a decrease in the spacing between the fibers. For the purpose of this study, the conservation of volume argument provides a plausible solution. However, further investigations into different weave patterns should be performed to develop a universal conservation of volume law to define the increasing thickness of fabric with respect to shear angle.

The cubic polynomial fit was chosen for the potential benefits it can have within a finite element model. Unlike a trigonometric function, the derivative of a polynomial can be easily calculated and implemented into a model. The polynomial fit of the data was created using the curve fit function within Microsoft Excel. The change in thickness followed a cubic relationship with the shear angle in the fabric reinforcement. Both fits were sufficient for estimating the thickness of the plates for the five reinforcement shear angles investigated in this paper. To justify the use of either of these curves for further analysis, future studies should be performed on a variety of fabrics over a wide span of shear angles within the reinforcements.

An important characteristic used to determine the mechanical properties of the composite is the fiber volume fraction. To investigate the density of the plates with respect to shear angle, the mass of each plate was measured. Fig. 9(a) indicates that the mass also increases with increasing shear angle. The density of each plate was then calculated based on the assumed rectangular volume determined from the measured length, width, and thicknesses. Fig. 9(b) shows that the densities of 
the plates are independent of the shear angle in the fabric reinforcement. The rule of mixtures defines the composite density as a linear function:

$$
\rho=v_{f} \rho_{f}+\left(1-v_{f}-v_{v}\right) \rho_{m}
$$

where $\rho$ is the density of the composite, $\rho_{f}$ is the density of the glass, and $\rho_{m}$ is the density of the polypropylene, $v_{f}$ is the fiber volume fraction, and $v_{v}$ is the volume fraction of any voids present in the sample. No voids were observed within any of the samples, so the void volume fraction can be assumed to be negligible. Eqn 5 can then be rearranged to indicate the density of the composite is directly proportional to the fiber volume fraction.

$$
\rho=v_{f}\left(\rho_{f}-\rho_{m}\right)+\rho_{m}
$$

Thus, the constant density shown in Fig. 9(b) indicates the shearing of the fabric reinforcements does not alter the fiber volume fraction for the manufacturing techniques used in this study.

\subsection{Bend Tests}

Bend tests were performed on the samples to investigate how the degree of shear within the textile reinforcement affected the flexural stiffness of each $127-\mathrm{mm} \times 127-\mathrm{mm}$ plate. Each plate was tested on an Instron 4464 universal testing machine with a 100-N load cell using a three-point bend test setup as is shown in Fig. 10. The supports were spaced 98-mm apart and a uniform deflection was applied across the middle of the plate. The tests were closely monitored to ensure that the deflection occurred within the linear-elastic range of the material. No material failure was observed during the tests.

Each plate was tested four times. Referring to the coordinate system defined in Fig. 6(b), the plate was first bent about the global Y-axis such that the weft tows experienced a bending load in the X-direction. The plate was then subsequently rotated by $90^{\circ}$ and bent about the global $\mathrm{X}$-axis such that it was loaded in the Y-direction. Each plate was assumed to be symmetric about its 
midplane because the plates consisted of a single ply of a balanced plain-weave fabric. To explore this assumption, each plate was then flipped over to apply a negative curvature to the global Xdirection and Y-direction, respectively. The load-displacement curve for a positive curvature was the same as the load-displacement curve for a negative curvature in each respective direction, confirming that the plates were composed of symmetric lamina.

The load-deflection results for the bend tests in the X-direction and the Y-direction are reported in Fig. 11(a) and Fig. 11(b), respectively. Each line represents the average of the loading and unloading curves as well as the positive and negative curvature for all three samples, and the error bars denote one standard deviation. Note, that in Fig. 11(a), the average $0^{\circ}$ load-displacement curve and the average $10^{\circ}$ load-displacement curve are nearly coincident. A similar trend was observed in Fig. 11(b) with the average $10^{\circ}$ load-displacement curve and the average $20^{\circ}$ loaddisplacement curves.

The slopes of the average load-displacement data are shown in Fig. 11(c) and Fig. 11(d) and are listed in Table 3. The square plate geometry used for the bend tests results in a transverse Poission effect. This effect makes calculating the bending modulus difficult. Because the slopes of the load-displacement curves are proportional to the bending stiffness of the plates, the trends observed in the load-displacement curves as a function of textile shear correlate with similar trends in the stiffnesses of the plates. Fig. 11 and Table 3 show that the stiffness of the plate in the Xdirection (i.e. aligned with the weft tows) increased as the fabric shear angle increased. This trend was expected because the warp tows rotate towards the $\mathrm{X}$-direction as the fabric is sheared. However, the results of the tests loaded in the Y-direction as shown in Fig. 11(b) were unexpected. Instead of the stiffness decreasing as the fibers were sheared away from the warp direction, the stiffness of the plates reinforced by fabrics with shear angles from $0^{\circ}$ to $25^{\circ}$ are essentially constant. 
Additionally, an unexpected increase in stiffness was observed in the $30^{\circ}$ sheared plates. A numerical investigation was subsequently pursued, and that study is reported in the Part 2 paper documenting this research.

\section{Discussion}

The current study examines the similarities between textile deformations observed within a dry textile and a consolidated composite plate as a result of shear deformation. The results observed indicate the behavior of a composite plate reinforced by sheared fabrics are not intuitive and should be the subject of future research. However, the geometric changes observed in the textilereinforcements observed in this study are potentially unique to a pure-shear deformation state. The complex modes of deformation, e.g. coupled shear, tension, and bending, observed during the forming of a composite part could conceivably result in different changes to the internal geometry, thus resulting in changes in the mechanical behavior of the composite.

Additionally, the boundary conditions imposed during composite forming have the potential to alter the geometry of the fabric. This study took advantage of a picture-frame rig to induce shear within the textile-reinforcement. Pretension within the fiber tows changes the shear stiffness of the fabric [14-16], which could hypothetically affect the geometry of the textile, resulting in a potential change in the composite's mechanical behavior. Similarly, forming parts with matched-dye tooling results in a part with a constant thickness. If the textile is constrained from increasing in thickness due to shear, as observed in this study, the fabric's geometry could be affected, resulting in a corresponding change to the composite's material properties.

The wide variety of composite forming processes and textiles provides a plethora of possible changes in the reinforcement's geometry. The current study indicates that these geometrical changes are significant to the mechanical behavior of the composite. Therefore, additional in-depth studies 
should be performed to understand how textile deformation translates to the internal geometry of the composite and how this geometry effects the mechanical properties of the composite.

\section{Conclusions}

As a textile-reinforced composite is formed, fiber tows will shear relative to each other to conform to the compound curvature features of a mold. The current study explored the effect of shear deformation on the geometry and bending stiffness of composite plates reinforced with a plain-weave fabric. Plates were manufactured with a pre-determined shear angle in the fabric reinforcement and then tested in flexure. Changes in the tow width were observed as a function of shear angle. When compared to literature results for dry fabric, the change in tow width was consistent with the geometrical deformation of the tow and no lateral compaction was observed. An increase in plate thickness was observed with increasing shear angle within the fabric reinforcement, which was consistent with the results reported in the literature for dry fabric. This change in thickness corresponded with a change in mass for the plates. The density was consistent amongst all the plates, indicating that the fiber volume fraction was independent of the shear angle present within the textile reinforcement. All of the deformations were observed on a single fabric architecture. Further explorations should be performed to determine if these observations are specific to the factors such as weave type, tow width, and tow spacing.

Each plate was subjected to a three-point bend test in each direction. The change in bending stiffness of the plates as a function of fabric shear displayed trends that were not solely consistent with reorientation of the fibers. The stiffness of the plates in the X-direction (i.e. the direction that the fibers were being sheared towards) increased with increasing shear angle as expected. However, the stiffness of the plates in the Y-direction (i.e. the direction that the fibers were being sheared away from) decreased for small shear angles and increased for large shear angles. 


\section{Acknowledgements}

The authors would like to acknowledge the National Science Foundation for its support of

this research through Award No. 1230884.

\section{REFERENCES}

[1]. Brøndsted P, Lilholt H, Lystrup A. Composite materials for wind power turbine blades. Annu Rev Mater Res. 2005;35:505-38.

[2]. Jones RM. Mechanics of composite materials: CRC Press; 1998.

[3]. Shivakumar KN, Swaminathan G, Sharpe M. Carbon/vinyl ester composites for enhanced performance in marine applications. Journal of Reinforced Plastics and Composites. 2006;25(10):1101-16.

[4]. Veers PS, Ashwill TD, Sutherland HJ, Laird DL, Lobitz DW, Griffin DA, et al. Trends in the Design, Manufacture and Evaluation of Wind Turbine Blades. Wind Energy. 2003;6(3):24559.

[5]. Hoa SV. Principles of the Manufacturing of Composite Materials. DEStech Publications; 2009.

[6]. Hyer MW, White SR. Stress Analysis of Fiber-reinforced Composite Materials: DEStech Publications, Incorporated; 2009.

[7]. Strong AB. Fundamentals of Composites Manufacturing - Materials, Methods, and Applications (2nd Edition). Society of Manufacturing Engineers (SME); 2008.

[8]. Mallick PK. Fiber-reinforced composites: materials, manufacturing, and design: CRC press; 1993.

[9]. Cao J, Akkerman R, Boisse P, Chen J, Cheng H, De Graaf E, et al. Characterization of mechanical behavior of woven fabrics: experimental methods and benchmark results. Composites Part A: Applied Science and Manufacturing. 2008;39(6):1037-53.

[10]. Lin, Guochang, Xuebo Yuan, Xilin Luo, Ge He, and Huifeng Tan. "Effect of misalignment on shear response of plain woven fabric in picture frame test: experiments and finite element modelling." The Journal of The Textile Institute (2015): 1-9.

[11]. J. Chen, D.S. Lussier, J. Cao, X.Q. Peng, Materials characterization methods and material models for stamping of plain woven composites, Int J Forming Process, 4 (2001), pp. 269-283

[12]. S.H. Chang, S.B. Sharma, M.P.F. Sutcliffe, Microscopic investigation of tow geometry of dry satin weave fabric during deformation, Compos Sci Technol, 63 (2003), pp. 99-111

[13]. Komeili, M. and Milani, A.S., 2013. Shear response of woven fabric composites under mesolevel uncertainties. Journal of Composite Materials, 47(19), pp.2331-2341.

[14]. Launay, J., Hivet, G., Duong, A. V., \& Boisse, P. (2008). Experimental analysis of the influence of tensions on in plane shear behaviour of woven composite reinforcements. Composites Science and Technology, 68(2), 506-515.

[15]. G. Hivet, V.A. Duong, A contribution to the analysis of the intrinsic shear behavior of fabrics, J Compos Mater, 45 (6) (2010), pp. 695-716

[16]. Harrison, P., Abdiwi, F., Guo, Z., Potluri, P., \& Yu, W. R. (2012). Characterising the sheartension coupling and wrinkling behaviour of woven engineering fabrics. Composites Part A: Applied Science and Manufacturing, 43(6), 903-914. 
[17]. Ishikawa T, Chou TW. Stiffness and strength behaviour of woven fabric composites. Journal of Materials Science. 1982;17(11):3211-20.

[18]. Barbero EJ. Introduction to composite materials design: CRC press; 2010.

[19]. Carvelli V, Poggi C. A homogenization procedure for the numerical analysis of woven fabric composites. Composites Part A: Applied Science and Manufacturing. 2001;32(10):1425-32.

[20]. Badel P, Vidal-Sallé E, Maire E, Boisse P. Simulation and tomography analysis of textile composite reinforcement deformation at the mesoscopic scale. Composites Science and Technology. 2008;68(12):2433-40.

[21]. Boisse P, Gasser A, Hagege B, Billoet J-L. Analysis of the mechanical behavior of woven fibrous material using virtual tests at the unit cell level. Journal of materials science. 2005;40(22):5955-62.

[22]. Boisse P, Hamila N, Helenon F, Hagege B, Cao J. Different approaches for woven composite reinforcement forming simulation. Int J Mater Form. 2008;1(1):21-9.

[23]. Boisse P, Hamila N, Vidal-Sallé E, Dumont F. Simulation of wrinkling during textile composite reinforcement forming. Influence of tensile, in-plane shear and bending stiffnesses. Composites Science and Technology. 2011;71(5):683-92.

[24]. Cherouat A, Borouchaki H, Giraud-Moreau L. Mechanical and geometrical approaches applied to composite fabric forming. Int J Mater Form. 2010;3(2):1189-204.

[25]. Dangora LM, Mitchell CJ, Sherwood JA. Predictive Model for the Detection of Out-of-Plane Defects Formed during Textile-Composite Manufacture. Composites Part A: Applied Science and Manufacturing. Accepted July 2015.

[26]. K. A. Fetfatsidis, C. Mitchell, J. A. Sherwood, E. Harvey, P. Avitabile, "Simulating the Manufacturing Process and Subsequent Structural Stiffness of Composite Wind Turbine Blades with and without Defects", Key Engineering Materials, Vols. 504-506, pp. 249-254, 2012

[27]. Harrison P, Yu W-R, Long AC. Rate dependent modelling of the forming behaviour of viscous textile composites. Composites Part A: Applied Science and Manufacturing. 2011;42(11):1719-26.

[28]. Jauffrès D, Sherwood J, Morris C, Chen J. Discrete mesoscopic modeling for the simulation of woven-fabric reinforcement forming. Int J Mater Form. 2010;3(2):1205-16.

[29]. Morris CD, Dangora LM, Sherwood JA. Using LS-DYNA® to Simulate the Thermoforming of Woven-Fabric Reinforced Composites. 13th LS-DYNA® International Conference \& User Meeting: Dearborn, MI; 2014.

[30]. Peng X, Cao J. A continuum mechanics-based non-orthogonal constitutive model for woven composite fabrics. Composites part A: Applied Science and manufacturing. 2005;36(6):85974.

[31]. Ramakrishna S. Analytical and finite element modeling of elastic behavior of plain-weft knitted fabric reinforced composites. Key Engineering Materials. 1997;137:71-8.

[32]. Sherwood JA, Jauffres D, Fetfatsidis K, Winchester D, Chen J. Mesoscopic finite element simulation of the compression forming of sheet molding compound woven-fabric composites. 9th Annual Automotive Composites Conference and Exhibition, ACCE 2009, September 15, 2009 - September 16, 2009. Troy, MI, United states: SPE Automotive and Composites Division; 2009. p. 847-63.

[33]. Ten Thije R, Akkerman R, Huetink J. Large deformation simulation of anisotropic material using an updated Lagrangian finite element method. Computer methods in applied mechanics and engineering. 2007;196(33):3141-50. 
[34]. Lomov SV, Huysmans G, Luo Y, Parnas R, Prodromou A, Verpoest I, et al. Textile composites: modelling strategies. Composites Part A: applied science and manufacturing. 2001;32(10):1379-94.

[35]. Mitchell C, Sherwood J , Fetfatsidis K, Dangora L. Characteriziation of Cured NCF Composites used in the Forming of Wind Turbine Blades. $19^{\text {th }}$ International Conference on Composite Materials: Montreal, Canada; 2013.

[36]. Bel S, Hamila N, Boisse P, Dumont F. Finite element model for NCF composite reinforcement preforming: Importance of inter-ply sliding. Composites Part A: Applied Science and Manufacturing. 2012;43(12):2269-77.

[37]. Carvelli V, Pazmino J, Lomov SV, Verpoest I. Deformability of a non-crimp 3D orthogonal weave E-glass composite reinforcement. Composites Science and Technology. 2012;73:9-18.

[38]. Dangora L, Hansen C, Mitchell C, Parker J, Sherwood J. Challenges Associated with Shear Characterization of a Cross-ply Thermoplastic Lamina using Picture Frame Tests. Composites Part A: Applied Science and Manufacturing. 2015;78:181-190.

[39]. Guzman-Maldonado, E., Hamila, N., Boisse, P. and Bikard, J. Thermomechanical analysis, modelling and simulation of the forming of pre-impregnated thermoplastics composites. Composites Part A: Applied Science and Manufacturing. 2015;78:211-222.

[40]. Guzman-Maldonado, E., Hamila, N., Naouar, N., Moulin, G. and Boisse, P. Simulation of thermoplastic prepreg thermoforming based on a visco-hyperelastic model and a thermal homogenization. Materials \& Design. 2016;93:431-442.

[41]. Harrison P, Abdiwi F, Guo Z, Potluri P, Yu W. Characterising the shear-tension coupling and wrinkling behaviour of woven engineering fabrics. Composites Part A: Applied Science and Manufacturing. 2012;43(6):903-14.

[42]. Lussier D, Chen J. Material characterization of woven fabrics for thermoforming of composites. Journal of Thermoplastic Composite Materials. 2002;15(6):497-509.

[43]. McGuinness G, ÓBrádaigh C. Characterisation of thermoplastic composite melts in rhombusshear: the picture-frame experiment. Composites Part A: Applied Science and Manufacturing. 1998;29(1):115-32.

[44]. Prodromou A, Chen J. On the relationship between shear angle and wrinkling of textile composite preforms. Composites Part A: Applied Science and Manufacturing. 1997;28(5):491-503.

[45]. Buckenham P. Bias-extension measurements on woven fabrics. Journal of the Textile Institute. 1997;88(1):33-40.

[46]. Harrison P, Gomes R, Curado-Correia N. Press forming a 0/90 cross-ply advanced thermoplastic composite using the double-dome benchmark geometry. Composites Part A: Applied Science and Manufacturing. 2013;54(0):56-69.

[47]. Li X. Material characterization of woven-fabric composites and finite element analysis of the thermostamping process [D.Eng.]: University of Massachusetts Lowell; 2005.

[48]. McBride T, Chen J. Unit-cell geometry in plain-weave fabrics during shear deformations. Composites science and technology. 1997;57(3):345-51.

[49]. Mohammed U, Lekakou C, Dong L, Bader M. Shear deformation and micromechanics of woven fabrics. Composites Part A: Applied Science and Manufacturing. 2000;31(4):299-308.

[50]. Wang J, Page J, Paton R. Experimental investigation of the draping properties of reinforcement fabrics. Composites Science and Technology. 1998;58(2):229-37. 
[51]. Chen S, Harper L, Endruweit A, Warrior N. Formability optimisation of fabric preforms by controlling material draw-in through in-plane constraints. Composites Part A: Applied Science and Manufacturing. 2015;76:10-9.

[52]. Zhu B, Yu T, Tao X. An experimental study of in-plane large shear deformation of woven fabric composite. Composites Science and Technology. 2007;67(2):252-61.

[53]. Barburski M, Lomov SV, Lanckmans F, de Ridder F, Verpoest I. Experimental Study of Steel and Glass Knitted Fabrics Thickness under Pre-Strain and Shear. Key Engineering Materials. 2013;554:385-90.

[54]. Ivanov DS, Van Gestel C, Lomov SV, Verpoest I. In-Situ Measurements of Fabric Thickness Evolution During Draping. AIP Conference Proceedings. 2011;1353(1):924-9.

[55]. Twintex(R) Thermoplastic Polypropylene Glass Roving. www.fiberglassindustries.com: Fiber Glass Industries; 2014. 


\section{FIGURES}

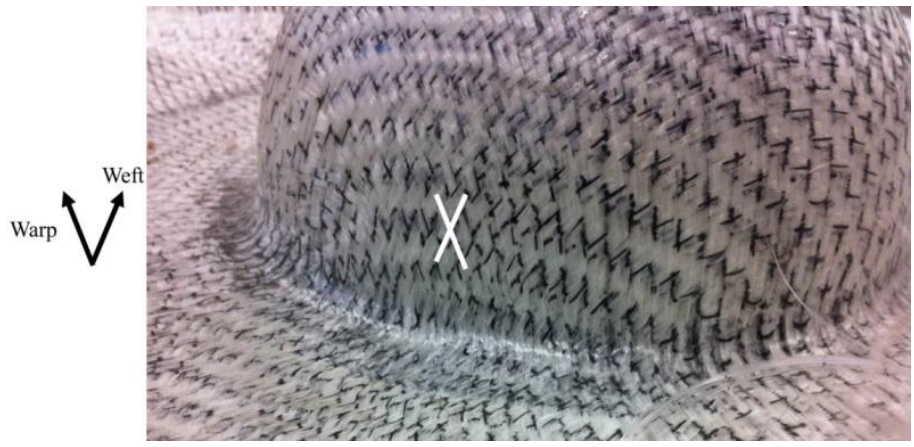

Fig. 1. Shear deformation of a woven fabric formed into a hemisphere.

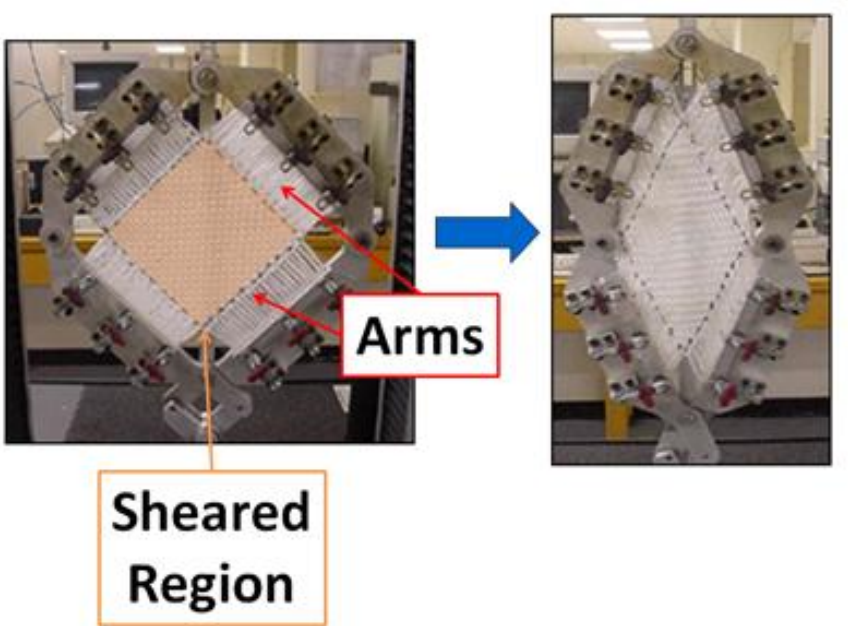

(a)

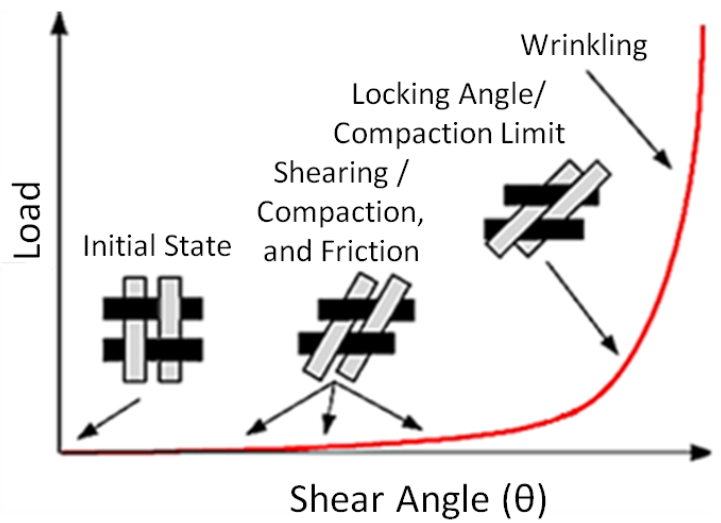

(b)

Fig. 2. Picture-frame (a) test setup and (b) typical load vs. shear angle response [32].

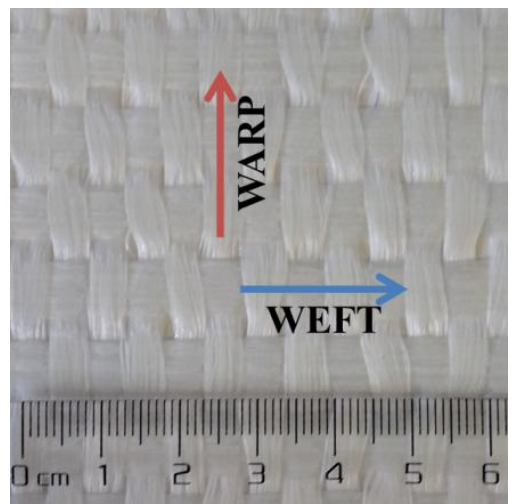

Fig. 3. Twintex $®$ fabric architecture. 

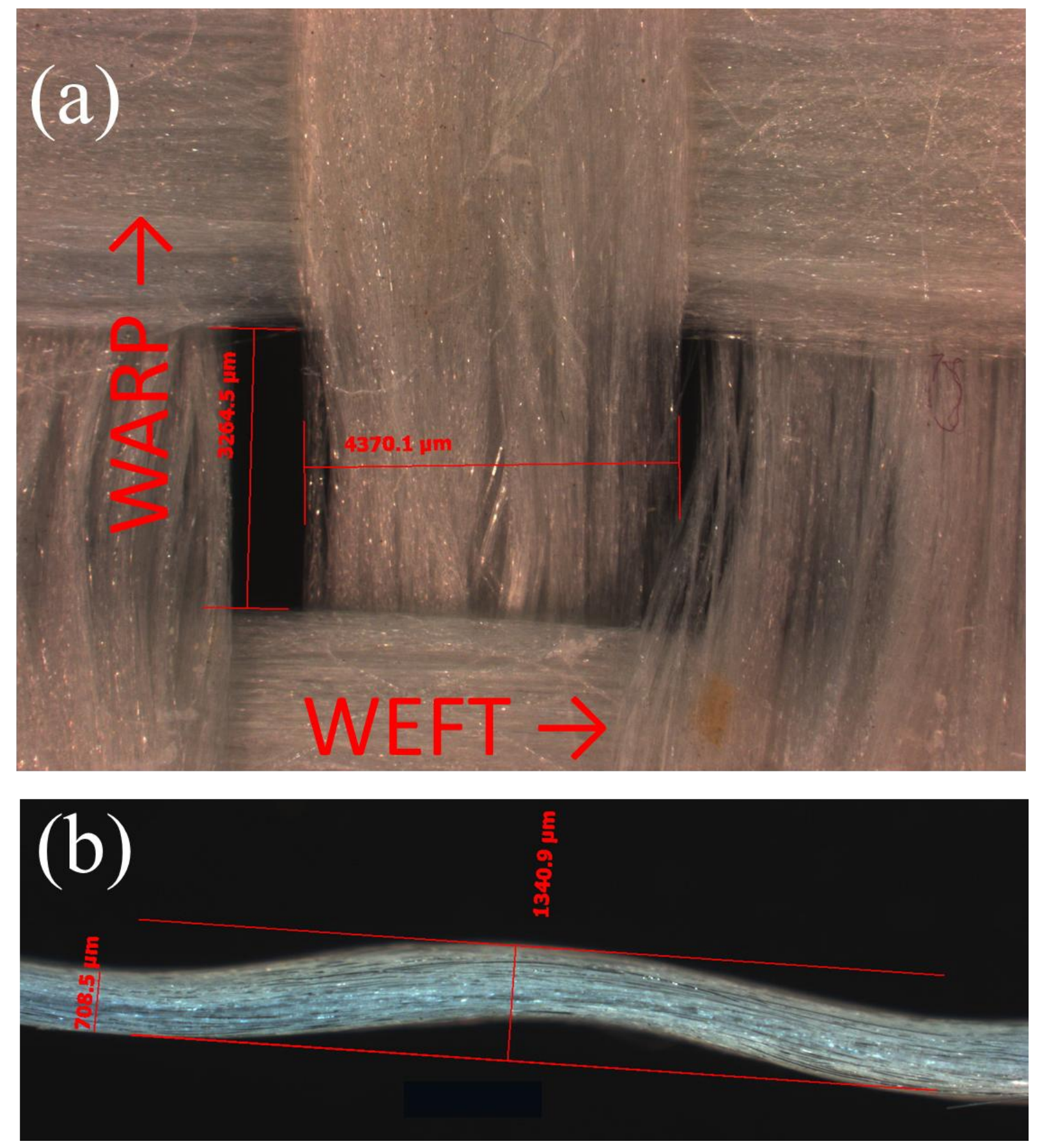

Fig. 4. Stereo Microscope images used to measure (a) tow width and tow spacing and (b) tow thickness and fabric thickness 


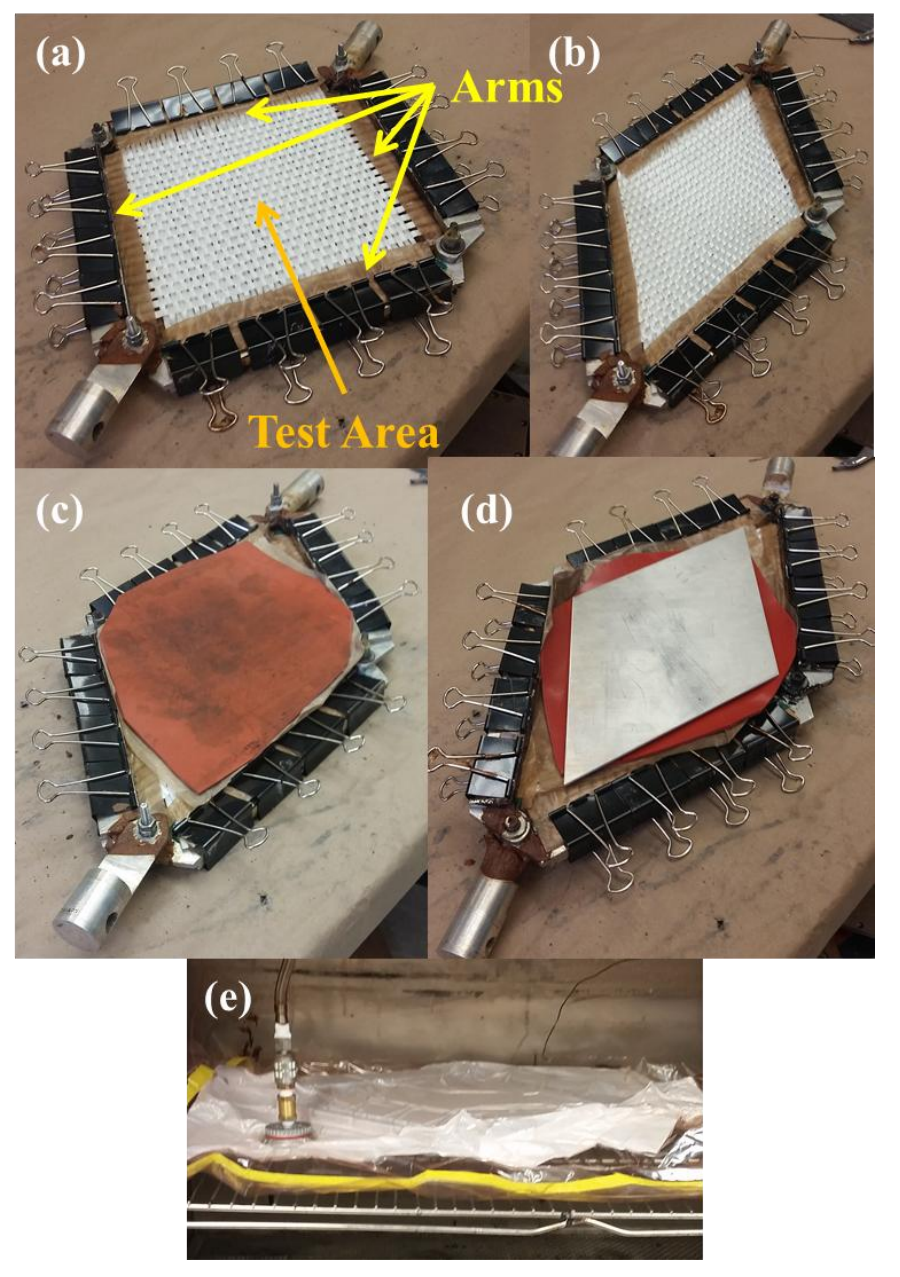

Fig. 5. Layup process for sheared-fabric-reinforced plates. 


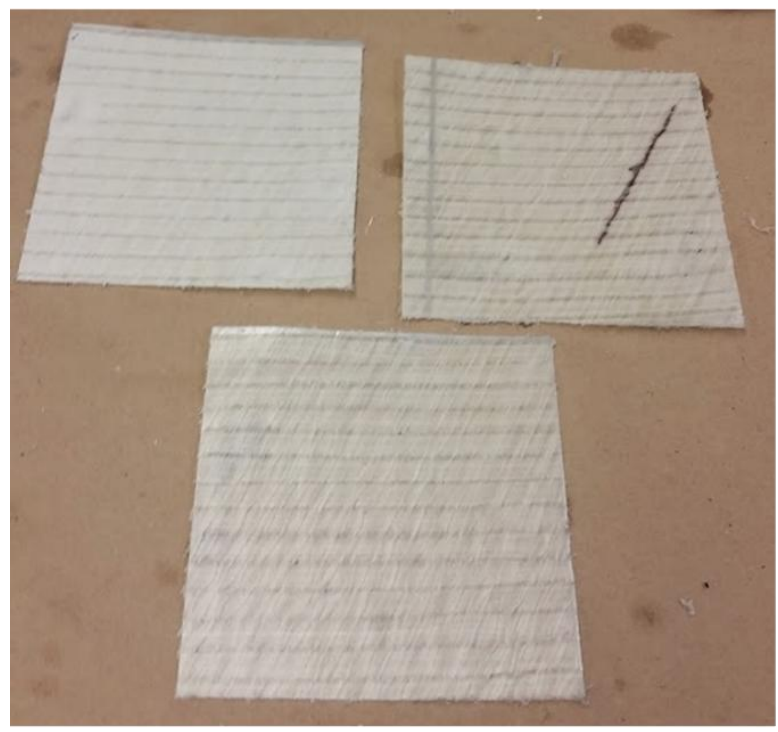

(a)

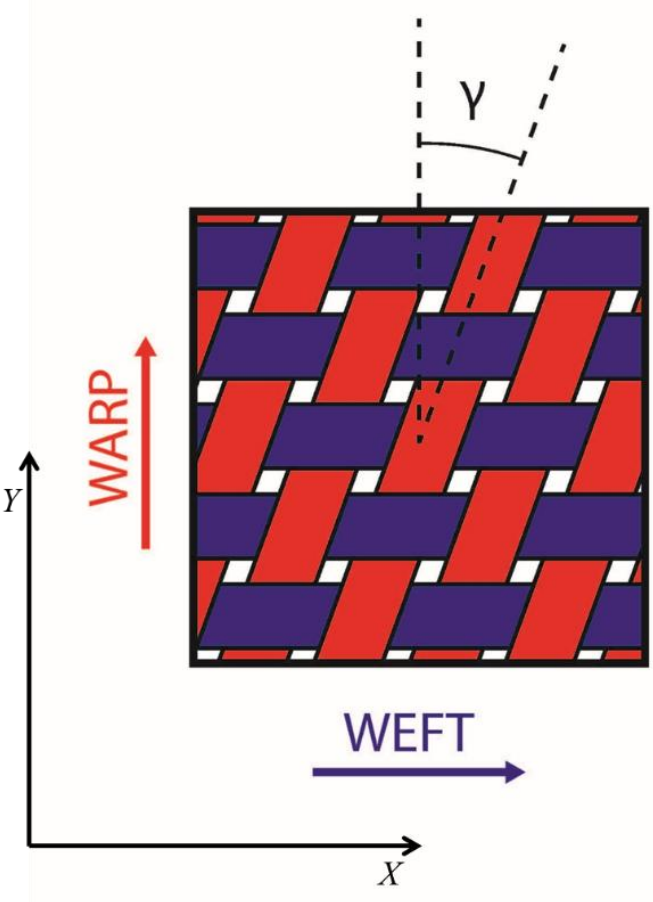

(b)

Fig. 6. (a) Twintex ${ }^{\circledR}$ plates manufactured with a $25^{\circ}$ shear angle in the fabric reinforcement and (b) schematic of sheared-fabric-reinforced plates.

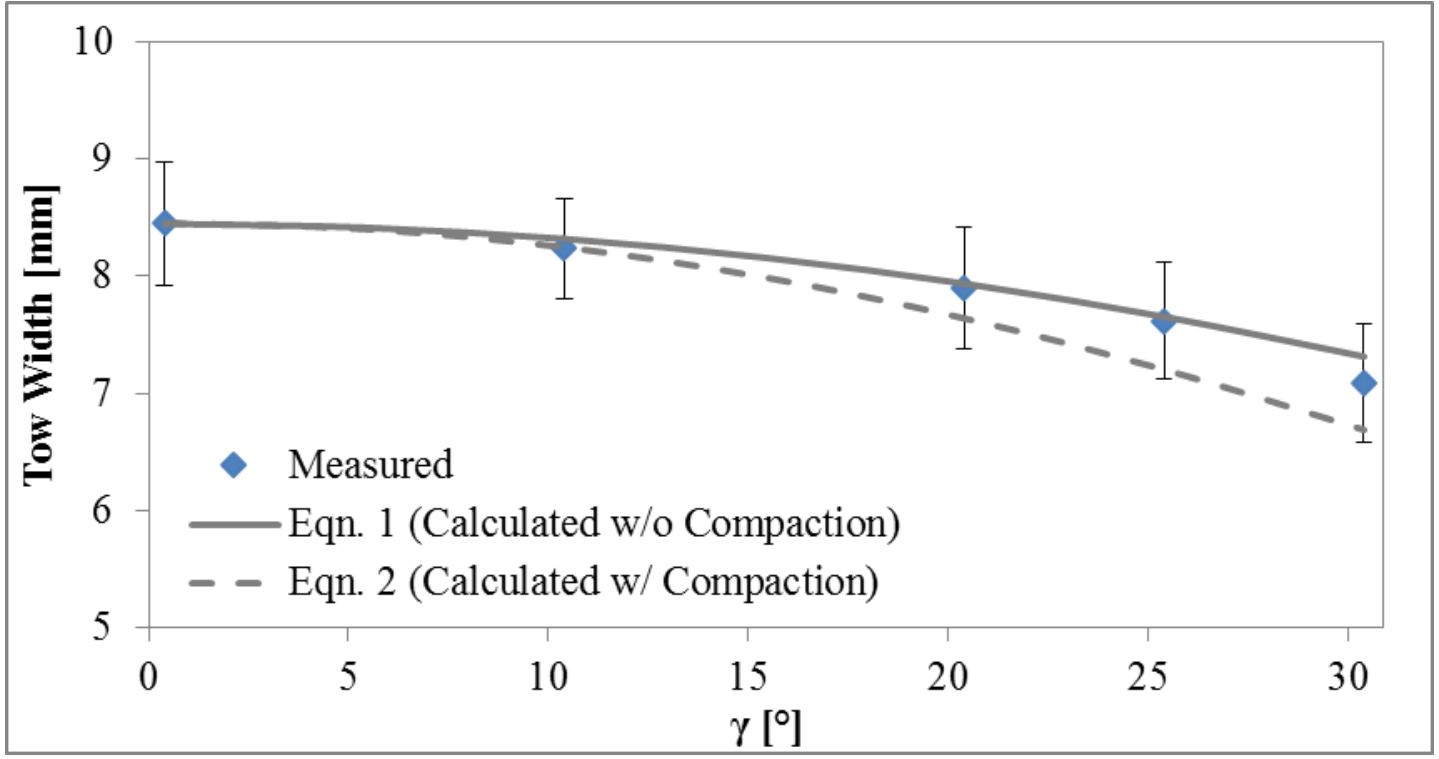

Fig. 7. Weft tow width as a function of reinforcement shear angle. 


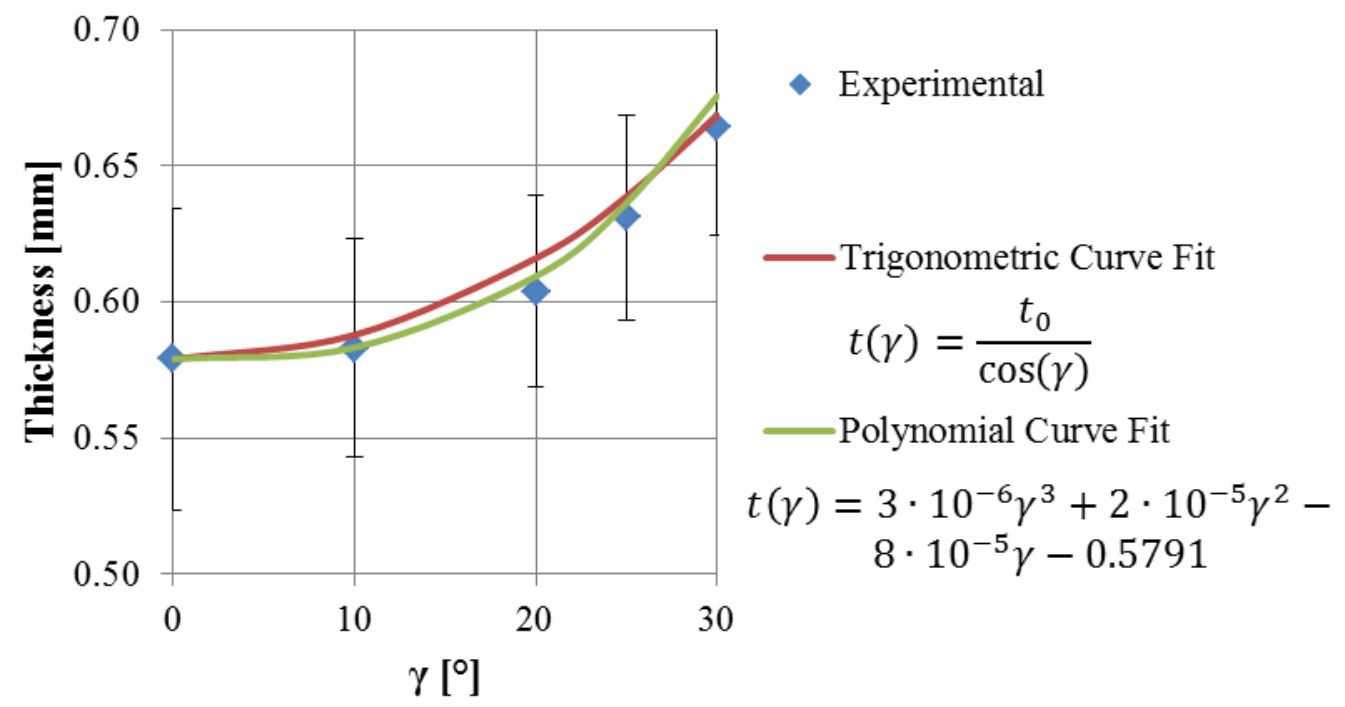

Fig. 8. Experimental measurements of plate thicknesses as a function of reinforcement shear angle compared to two possible functions to describe the data.

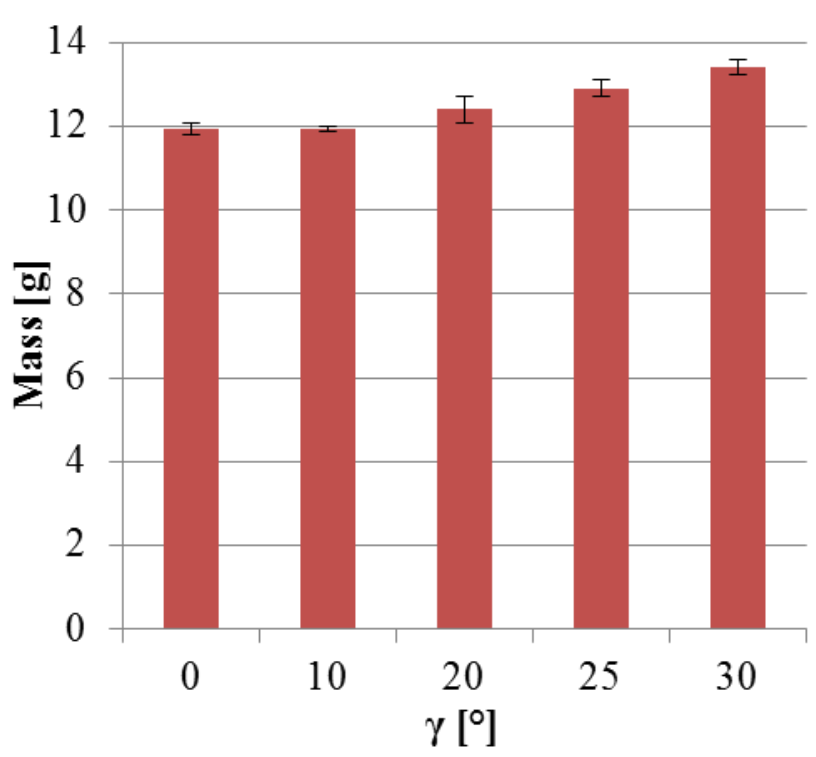

(a)

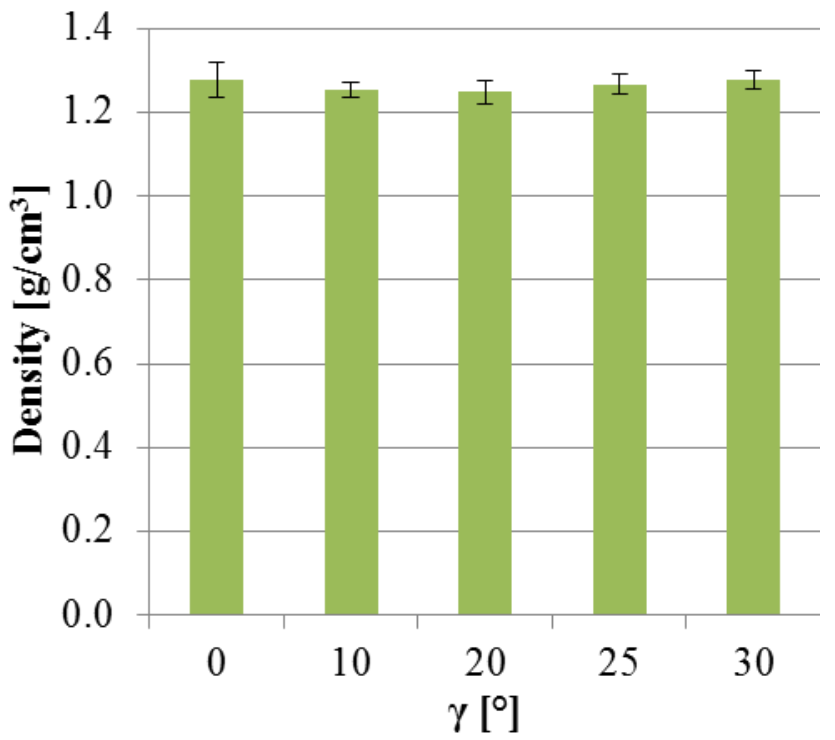

(b)

Fig. 9. Variation of (a) mass and (b) density with respect to reinforcement shear angle. 


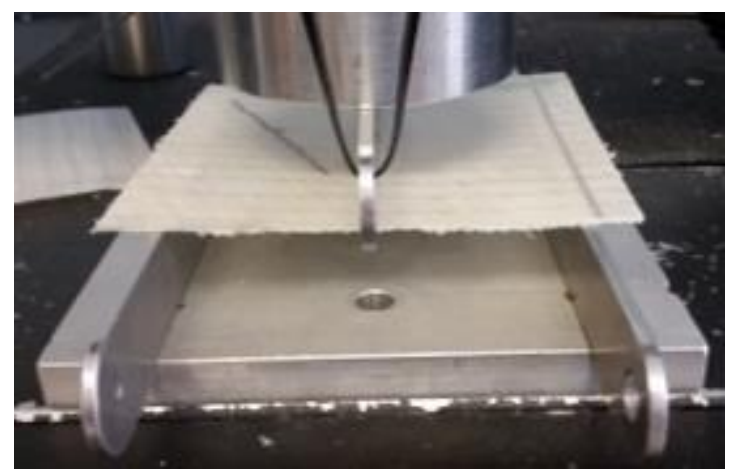

Fig. 10. Bend test experimental setup.

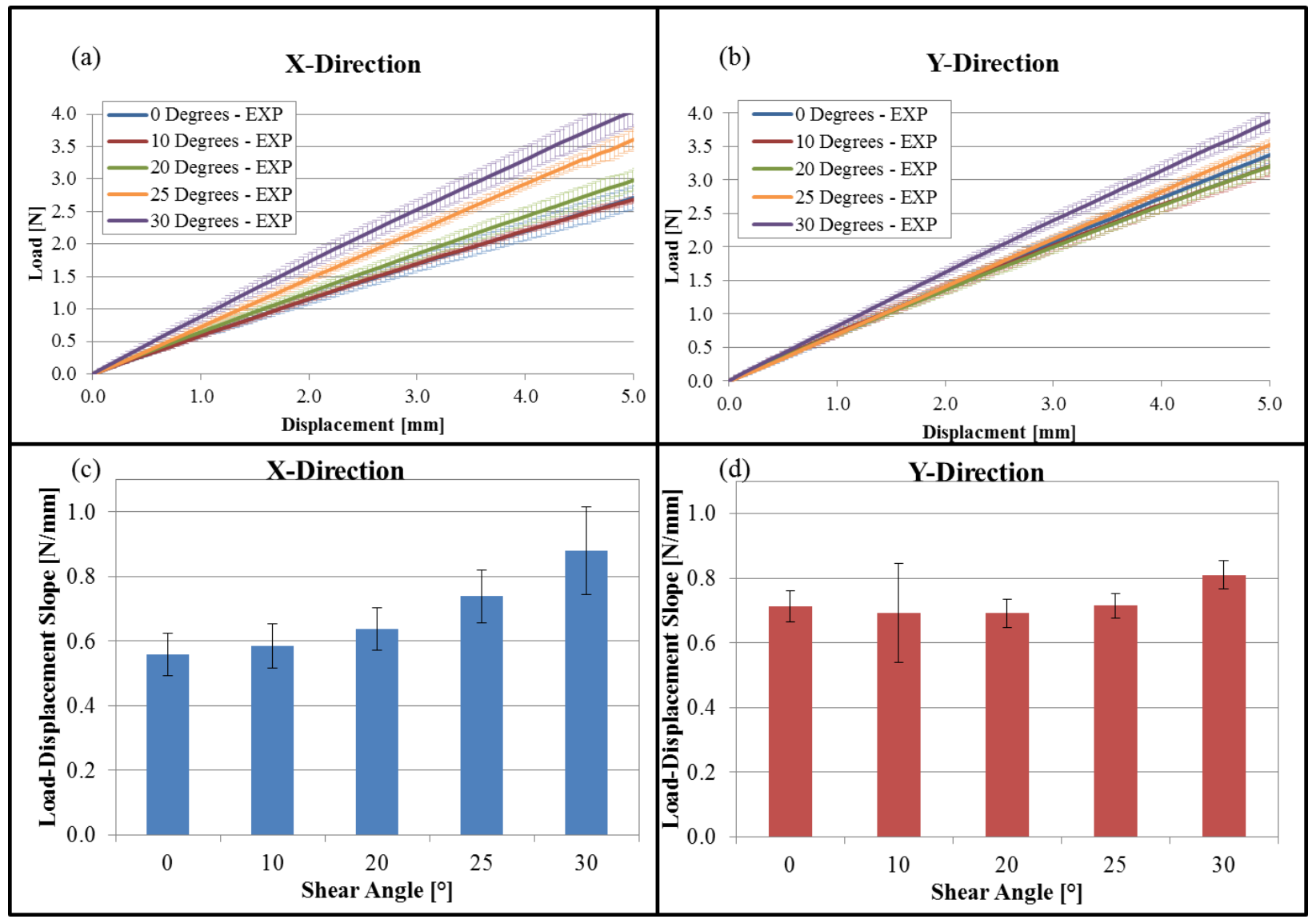

Fig. 11. Bend test load-displacement results for (a) X-direction and (b) Y-direction and the slopes of the load-displacement curves for (c) X-direction and (d) Y-direction 


\section{TABLES}

Table 1. Twintex $®$ Fabric Properties

\begin{tabular}{|c|c|c|c|}
\hline & & E-Glass & Polypropylene \\
\hline \multicolumn{4}{|c|}{ Fiber Properties } \\
\hline Volume Fraction & [\%] & 35 & 65 \\
\hline Elastic Modulus & [GPa] & 70 & 1.5 \\
\hline Density & {$\left[\mathrm{g} / \mathrm{cm}^{3}\right]$} & 2.6 & 0.9 \\
\hline \multicolumn{4}{|c|}{ Fabric Properties } \\
\hline Areal Density & {$\left[\mathrm{g} / \mathrm{m}^{2}\right]$} & \multicolumn{2}{|c|}{262} \\
\hline
\end{tabular}

Table 2. Average measured dimensions of Twintex ${ }^{\circledR}$ plain-weave fabric.

\begin{tabular}{|l|r|r|r|}
\hline \multicolumn{2}{|l|}{} & Warp & Weft \\
\hline \multicolumn{2}{|l|}{ Tow Dimensions } & & \\
\hline Width & {$[\mathrm{mm}]$} & $4.58 \pm 0.23$ & $6.92 \pm 0.20$ \\
\hline Height & {$[\mathrm{mm}]$} & $0.40 \pm 0.21$ & $0.70 \pm 0.19$ \\
\hline Area & {$\left[\mathrm{mm}^{2}\right]$} & $0.44 \pm 0.02$ & $0.90 \pm 0.02$ \\
\hline \multicolumn{2}{|l|}{ Fabric Dimensions } & & \\
\hline Gap & {$[\mathrm{mm}]$} & $0.43 \pm 0.28$ & $3.21 \pm 0.17$ \\
\hline Thickness & {$[\mathrm{mm}]$} & $1.20 \pm 0.20$ & $1.20 \pm 0.20$ \\
\hline
\end{tabular}

Table 3. Slopes of average load-displacement curves for plates with varying fabric shear angles.

\begin{tabular}{|c|c|c|c|c|}
\hline \multirow{2}{*}{$\begin{array}{l}\text { Shear } \\
\text { Angle } \\
\left.{ }^{\circ}\right]\end{array}$} & \multicolumn{2}{|l|}{ X-Direction } & \multicolumn{2}{|l|}{ Y-Direction } \\
\hline & $\begin{array}{l}\text { Avg. Slope } \\
{[\mathrm{N} / \mathrm{mm}]}\end{array}$ & $\begin{array}{l}\text { Std. } \\
\text { Dev. }\end{array}$ & $\begin{array}{l}\text { Avg. Slope } \\
{[\mathrm{N} / \mathrm{mm}]}\end{array}$ & $\begin{array}{l}\text { Std. } \\
\text { Dev. }\end{array}$ \\
\hline 0 & 0.558 & 0.037 & 0.714 & 0.035 \\
\hline 10 & 0.585 & 0.038 & 0.693 & 0.110 \\
\hline 20 & 0.638 & 0.036 & 0.692 & 0.031 \\
\hline 25 & 0.739 & 0.045 & 0.715 & 0.027 \\
\hline 30 & 0.880 & 0.076 & 0.810 & 0.031 \\
\hline
\end{tabular}

